\title{
Editorial: Action Research
}

\author{
Chris McPhee, Editor-in-Chief \\ Magnus Hoppe and Erik Lindhult, Guest Editors
}

\section{From the Editor-in-Chief}

Welcome to the May 2019 issue of the Technology Innovation Management Review. This is the second of two issues on the theme of Action Research, and it is my pleasure to continue our collaboration with guest editors Magnus Hoppe and Erik Lindhult from Mälardalen University in Sweden. Magnus and Erik are also both Board Member of the Swedish Interactive Research Association (SIRA), and Erik is a Board Member of the Swedish Participative Action Research Community (SPARC).

We hope that these two special issues on action research will both provide valuable insights and encourage further contributions in the field. As we are developing plans for future special issues on action research, we encourage potential authors to contact us to express interest in contributing articles.

Furthermore, our regular June issue will include an interview with David Coghlan, Professor Emeritus at the Trinity Business School, Trinity College Dublin, Ireland. David is one of the founding fathers of modern action research, and he will offer his reflections on the present and future of the theory and practice of action research, and he will comment on the patterns and insights he sees in these two special issues of the TIM Review.

Please contact us (timreview.ca/contact) with potential article topics and submissions, and proposals for future special issues. As always, we also welcome general submissions of articles on technology entrepreneurship, innovation management, and other topics relevant to launching and growing technology companies and solving practical problems in emerging domains.

\section{Chris McPhee}

Editor-in-Chief

\section{From the Guest Editors}

In April (timreview.ca/issue/2019/april), we published the first of this pair of special issues on the theme of Action Research. This second special issue can be said to be both a prolongation of the first issue and an expansion of the scope of the first issue. The aim, however, is the same: to express the action research discussion in an accessible manner such that academics, industry, and the public sector can adopt the frameworks, models, and ideas presented by the authors.

First, Erik Lindhult provides two complementary articles that we hope can be used as solid references on the philosophy of action research. They both rests on the notion that action research has an epistemology of its own that challenges traditional views on quality, objectivity, and reliability. We believe that this argumentation is much needed by all who struggle with the demands from scientific dogmas and traditions. As these ideas most likely can be viewed as controversial to many, we are looking forward to continuing the discussion in future issues of the TIM Review, and we hope readers will take up this call for further contributions on action research in this journal.

Erik's first article, "Rethinking Research Quality", reconstructs scientific inquiry from a praxis-oriented understanding of knowledge, pointing to wider opportunities for understanding and achieving research quality. From this point of view, the potential for research quality lies not in corresponding theory with reality but in warranting and enhancing the trustworthiness of achieving human ends. Erik argues that engagement and purposes are integrated in science, recognizing a distinguishing feature of action research in the focus on production of knowledge for worthwhile human purposes. He develops a wider framework for understanding purpose in science and its basis in validity, reliability, and the core characteristics of participatory and action research. The article is also rethinking validity, offering a broader landscape of validation than more traditional approaches. An implication is that good inquiry management is needed in order to mobilize a broader spectrum of purposes, forms of knowledge, and a collaborative capacity for inquiry of stakeholders. 


\title{
Editorial: Action Research
}

\author{
Chris McPhee, Magnus Hoppe, and Erik Lindhult
}

In Erik's second article, "Rethinking Objectivity and Reliability", he goes further in reconstructing research quality by rethinking objectivity and reliability. In addition to achieving objectivity through a passive, distant position and reliability through replication of research results and standardization, the article shows that it is fruitful to consider the "subjective" and active role of researchers and participants as vital in enabling scientific objectivity and reliability. Erik concludes the article by emphasizing that, by rethinking validity, reliability, and objectivity, and recognizing that substantially more active and participatory stances enable scientific excellence, we can expand the repertoire of strategies for promoting research quality and support the mainstreaming of this type of approach in the scientific community.

In the third article, we revisit the empirical grounds of action research via a case study in order to not blind ourselves with theories. In this article, Victoria Lakiza and Isabelle Deschamps from Polytechnique Montréal in Canada describe the mechanisms through which action research can create the desired change and impact in both industry and academia. Through their article, we gain insight into the main steps of a longitudinal action research program in a Canadian manufacturing company. In order to succeed, the authors emphasize the necessities of building trust, understanding the system, becoming part of the team, and iterating. This approach has led them to formulate six success factors revolving around adherence to the developing specifics of the process they are part of as well as a flexible attitude in all aspects of action research work. We venture to conclude from their work that, if you accept that the system is open, you must be open, too, in most aspects, in order to make an action research partnership work for all.

Then, in the fourth article, by Mats Holmquist and Anna Johansson from Halmstad university, we learn how interventions affected employee-driven innovation. Crucial to their approach was to give centre stage to the employees and make managers bystanders. However, even though managers learned about their employees' ideas and appreciated the innovation process, the resulting innovation ideas were not implemented due to other priorities. The authors conclude that the absorptive capacity simply was not there, and they indirectly stress that management need to take a greater responsibility for implementing desired innovations, not just encourage employees to participate in processes for formulating innovation ideas.

Next, Kristin Falk from the University College of Southeastern Norway and Gerrit Muller at the Embedded
Systems Institute in Eindhoven describe how master's students can conduct research in collaboration with industry. The study covers a period of 10 years and over 180 master's projects, where the students were working embedded in industrial companies during half of time of their studies. As results from their projects, about a fourth of the students managed to produce research that qualified for publication in international conferences and journals. The approach guaranteed basing research in real-world problems where Falk and Muller classify $80 \%$ percent of the papers to be within the domain of action research.

Finally, Bengt Wahlström from Mälardalen University in Sweden draws on his 30-plus years of experience of management consultancy to answer the question: "What can action research learn from business environment analysis?" With different examples, he emphasizes that there is not just one knowledge or learning process at work, but several, that need to be addressed while succeeding with consultancy and, thus, these are also important aspects to consider when doing action research. At the centre of this is acknowledging that there is more than one way of gaining access to a company and building a project. Nevertheless, management and those with the power to change need to be involved at some point.

Taken together, we notice some central themes present in the articles of this special issue. The main one, to us, is the idea of the researcher to be or become part of the team that work with the real-world problem the action and knowledge process is supposed to solve. It takes commitment to the cause as well as time in order to become embedded and continuously adapt. Thus, flexibility is key. This logic contrasts with traditional ideas of scientific rigour and control, meaning that action researchers need complementary views on quality, objectivity, and validity, which we hope we have provided through this special issue. These insights might help researchers to reach their ends, but they will not suffice at the practical end. Instead, through the accounts available here, we become aware that action research efforts do not trump organizational power structures. Instead, analyzing the organization, how it is run, and who has the power to change are vital when paving the way for innovations, whether they are developed through action research or not. Action research is thus nothing you should do on a whim. You should not to just plunge into the practice. Instead, you will do better if you study the water first and decide when, where, and how to jump.

\section{Magnus Hoppe and Erik Lindhult Guest Editors}




\section{Editorial: Action Research}

\section{About the Editors}

Chris McPhee is Editor-in-Chief of the Technology Innovation Management Review. Chris holds an MASc degree in Technology Innovation Management from Carleton University in Ottawa, Canada, and BScH and MSc degrees in Biology from Queen's University in Kingston, Canada. He has 20 years of management, design, and content-development experience in Canada and Scotland, primarily in the science, health, and education sectors. As an advisor and editor, he helps entrepreneurs, executives, and researchers develop and express their ideas.

Magnus Hoppe is an Associate Professor at the School of Economics, Society and Engineering at Mälardalen University, Sweden. At the university, he is member of the Faculty Board and leads processes for collaborative research in sustainable development. Magnus holds a PhD in Business Administration from Åbo Akademi University in Finland, where he presented his thesis on organized intelligence work in modern organizations. His current research concerns both private and public organizations and spans intelligence, entrepreneurship, and innovation. A special research interest lies in questioning dominating perspectives that bind our understanding of specific topics, and he now works to establish new ways of talking and thinking about innovation. His aim is to help organizations build new insights that will enhance their ideation processes and strategy building and, thereby, improve their innovative capabilities.

Erik Lindhult (Ph.D.) is a Senior Lecturer in Innovation Management and Entrepreneurship at Mälardalen University in Sweden. He received his doctoral degree in Industrial Management from the Royal Institute of Technology in Stockholm, in the area of Scandinavian dialogue democratic approach to innovation and action research. His main area of research is participatory, collaborative, and democratic innovation and change management, as well as entrepreneurship for a sustainable development of society. His research interests also involve collaborative research methodologies, including action research and interactive research. He has been involved in a wide range of collaborative R\&D projects in the private, public, and cooperative sectors, in areas such as organizational development, incubator and science park development, service innovation, societal entrepreneurship, sustainable innovation, and school development. $\mathrm{He}$ is a board member of the Swedish Participatory Action Research Society (SPARC) and the Swedish Interactive Research Association (SIRA), as well as an expert advisor to the EU SWAFS Horizon 2020 research committee.
Citation: McPhee, C., Hoppe, M., \& Lindhult, E. 2019. Editorial: Action Research. Technology Innovation Management Review, 9(5): 3-5. http://doi.org/10.22215/timreview/1236

Keywords: action research, participatory research, participative, innovation 


\section{Academic Affiliations and Funding Acknowledgements}
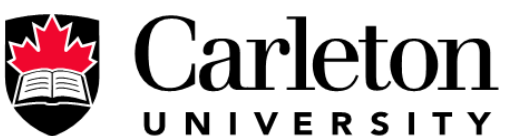

U N I V E R S I T Y

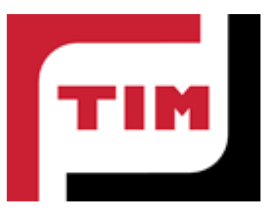

Technology Innovation Management (TIM; timprogram.ca) is an international master's level program at Carleton University in Ottawa, Canada. It leads to a Master of Applied Science (M.A.Sc.) degree, a Master of Engineering (M.Eng.) degree, or a Master of Entrepreneurship (M.Ent.) degree. The objective of this program is to train aspiring entrepreneurs on creating wealth at the early stages of company or opportunity lifecycles.

- The TIM Review is published in association with and receives partial funding from the TIM program. 